\title{
Comparison of regime-sorted tropical cloud profiles observed by CloudSat with GEOS5 analyses and two general circulation model simulations
}

\author{
Hui $\mathrm{Su},{ }^{1}$ Jonathan H. Jiang, ${ }^{1}$ Joao Teixeira, ${ }^{1}$ Andrew Gettelman, ${ }^{2}$ Xianglei Huang, ${ }^{3}$ \\ Graeme Stephens, ${ }^{1}$ Deborah Vane, ${ }^{1}$ and Vincent S. Perun ${ }^{1}$ \\ Received 27 August 2010; revised 17 February 2011; accepted 25 February 2011; published 11 May 2011.
}

[1] CloudSat observed tropical liquid and ice water content (L/IWC, Version 4) profiles are compared with GEOS5 analyses, NCAR-CAM3, and GFDL-AM2 simulations.

Both the analyses and free-running general circulation models (GCMs) underestimate IWC in the upper troposphere, with the simulated ice water paths (IWPs) being $22 \%$ (GEOS5), 9\% (CAM3), and 54\% (AM2) of the CloudSat retrieval. For liquid clouds, GEOS5 produces the closest match to CloudSat, with a distinct peak in LWC around $1.5-2 \mathrm{~km}$. CAM3 and AM2 generate liquid clouds in a broad vertical layer in the lower and middle troposphere, resulting in slightly higher column-integrated liquid water path (LWP) than CloudSat, despite the fact that their LWC in the boundary layer is only $60 \%-70 \%$ of CloudSat. The data assimilation model and two GCMs produce substantial middle-level clouds, more than the CloudSat retrieval. We sort the cloud profiles by midtropospheric vertical velocity $\left(\omega_{500}\right)$, sea surface temperature (SST), and lower tropospheric stability (LTS). The high clouds in the models are concentrated in large-scale ascending, warm SST, and low LTS regimes, consistent with the CloudSat observation. The CAM3 and AM2 model-simulated middle-level clouds are strongly correlated with $\omega_{500}$ but less clustered in the domains of SST and LTS. For low clouds, both CloudSat and GOES5 analyses show the preferential distribution of low clouds in regions of large-scale subsidence, relatively cold SST $\left(\mathrm{SST}<27^{\circ} \mathrm{C}\right.$ ), and high LTS (LTS $>15 \mathrm{~K}$ ), while CAM3 and AM2 low clouds are strongly controlled by SST and LTS and only weakly correlated with $\omega_{500}$. Exclusion of precipitating scenes would reduce the tropical mean CloudSat LWP and IWP by $73 \%$ and $48 \%$, respectively, which does not fully explain the model-data discrepancies.

Citation: Su, H., J. H. Jiang, J. Teixeira, A. Gettelman, X. Huang, G. Stephens, D. Vane, and V. S. Perun (2011), Comparison of regime-sorted tropical cloud profiles observed by CloudSat with GEOS5 analyses and two general circulation model simulations, J. Geophys. Res., 116, D09104, doi:10.1029/2010JD014971.

\section{Introduction}

[2] Accurate representation of clouds in general circulation models (GCMs) has been a challenge for the modeling community for decades [e.g., Cess et al., 1989, 1996; Stephens, 2005; Intergovernmental Panel on Climate Change, 2007]. A key to improve cloud simulations is to improve (both deep and shallow) cumulus parameterization and cloud microphysical schemes, which rely on a better understanding of the relationships between clouds and their environmental con-

\footnotetext{
${ }^{1}$ Jet Propulsion Laboratory, California Institute of Technology, Pasadena, California, USA.

${ }^{2}$ National Center for Atmospheric Research, Boulder, Colorado, USA.

${ }^{3}$ Department of Atmospheric, Oceanic, and Space Sciences, University of Michigan, Ann Arbor, Michigan, USA.

Copyright 2011 by the American Geophysical Union. 0148-0227/11/2010JD014971
}

ditions. Global surveying of cloud profiles and corresponding large-scale conditions is conducted by NASA A-Train satellites, which fly in formation and provide collocated and coincident measurements of clouds and their environmental dynamic and thermodynamic conditions [L'Ecuyer and Jiang, 2010]. In particular, CloudSat, a member of the A-Train, which carries a Cloud Profiling Radar (CPR) operating at $94 \mathrm{GHz}$, provides the first global measurement of cloud vertical profile since 2006. Based on measured radar reflectivity (RR), liquid and ice water contents (L/IWC) are retrieved [Austin et al., 2009]. Other instruments on board the A-Train provide important nearly simultaneous measurements of atmospheric and oceanic environmental conditions. For example, the Atmospheric Infrared Sounder (AIRS) on the Aqua satellite measures atmospheric temperature and water vapor profiles. The Advanced Microwave Scanning Radiometer-Earth Observing System (AMSR-E) provides global sea surface temperature (SST) in both clear-sky and cloudy conditions. Combining these 
measurements together, we are better positioned to understand cloud dynamics and physics than ever before.

[3] A method that sorts cloud properties and cloud radiative forcings by associated dynamic and thermodynamic regimes has proved to be useful in identifying factors that control cloud changes and deficiencies in model physics, as exemplified in a number of earlier studies [e.g., Bony et al., 2004; Bony and Dufresne, 2005; Huang et al., 2006; Williams et al., 2003; Wyant et al., 2006; Bennhold and Sherwood, 2008]. We refer to this method as "conditional sampling" approach, or "regime-sorting" technique. In the work by Bony et al. [2004], monthly mean vertical pressure velocity at $500 \mathrm{hPa}\left(\omega_{500}\right)$ was used as an index of large-scale circulation regimes to sort tropical cloud forcing and cloud response to climate perturbations, so that the dynamic and thermodynamic components of cloud changes could be better understood. Bony and Dufresne [2005] further applied the regime-sorting technique and showed that the spread of cloud climate sensitivities among models is more pronounced in the subsidence regime where boundary layer clouds dominate than in the ascending regime where deep convective clouds dominate. Huang et al. [2006] sorted model-observation difference in the top-of-atmosphere (TOA) fluxes in water vapor channels by $\omega_{500}$ to establish the linkage between modeled biases in radiative fluxes and the circulation regime. Williams et al. [2003] sorted model-simulated tropical cloudiness by $\omega_{500}$ and SST and compared with data from the Earth Radiation Budget Experiment (ERBE) and the International Satellite Cloud Climatology Project (ISCCP). They found that using SST in addition to $\omega_{500}$ added a clearer separation of stratocumulus and shallow cumulus, and provided additional perspective of cloud variations with large-scale conditions. Bennhold and Sherwood [2008] expanded the conditional sampling analysis of cloud radiative forcing to lower tropospheric precipitable water and static stability, and compared satellite observations to coupled climate model simulations. Wyant et al. [2006] compared $\omega_{500}$-sorted cloud properties (i.e., cloud forcing, cloud fraction and cloud water content, CWC) in three U.S. atmospheric GCMs to limited observations. They showed that large discrepancies exist among models. For CWC, no observations were available at that time. Thus, only column-integrated liquid water path (LWP) from the Special Sensor Microwave Imager (SSM/I) [Weng and Grody, 1994] and the Tropical Rainfall Measuring Mission (TRMM) Microwave Imager (TMI) [Wentz, 1997] were used to compare with the model results, leaving the vertical stratification of clouds largely unconstrained.

[4] The advent of CloudSat data offers an opportunity to examine vertical profiles of clouds. Using CloudSat data, Zhang et al. [2007] performed a cluster analysis on CloudSat RR and identified several tropical cloud regimes, consistent with the Weather States (WSs) defined by Rossow et al. [2005] using the ISCCP data. Zhang et al. [2007] also sorted the relative occurrence frequency of RR by $\omega_{500}$ and showed that deep convective and anvil clouds are common in large-scale ascending regions, while stratus and shallow cumulus are common over descending regions. $\mathrm{Su}$ et al. [2008] sorted CloudSat retrieved L/IWC by a number of large-scale dynamic and thermodynamic quantities, including $\omega_{500}$, SST, surface divergence, SST gradient, precipitation, water vapor path, convective available potential energy and lower tropospheric stability (LTS, the potential temperature difference between $700 \mathrm{hPa}$ and $1000 \mathrm{hPa}$, following the definition given by Klein and Hartmann [1993]). They confirmed that the deep and shallow clouds represented by peak CWCs are clearly associated with different large-scale regimes, consistent with the conventional wisdom for tropical clouds. They also reported that the middle-level clouds are less evident in the retrieved CWC profiles than the high and low clouds. The regime-sorted cloud profiles demonstrate the linkage between cloud structure and large-scale regimes and serve as new metrics to evaluate model simulations of clouds.

[5] A few studies have utilized the CloudSat data for model evaluations. Bodas-Salcedo et al. [2008] developed a "CloudSat Simulator" in the UK Met Office Unified Model (MetUM) and compared the simulated RR with CloudSat measured RR. They pointed out the underestimate of middle-level clouds occurrence frequency and the high bias of drizzle intensity in the MetUM. Given that there are no direct observations of cloud particle size, the conversion of modeled hydrometers to RR has large uncertainties. In GCMs, an issue that remains to be resolved is how to take into account the parameterized condensate in cumulus clouds into RR. On the other hand, the CloudSat retrieval applies the best available information of cloud particle size and temperature from the European Center for MediumRange Weather Forecasts (ECMWF) analysis to produce L/IWC profiles from RR [Austin et al., 2009]. Various validation efforts, including comparisons with other satellites and ground-based measurements, have been conducted to ensure that the retrievals represent our best knowledge of clouds that produce the measured radar signals. Thus, it is beneficial to compare the retrieved L/IWC directly with model outputs. Li et al. [2008] and Waliser et al. [2009] compared CloudSat L/IWC with a number of climate models and analysis data. They found that some model results could differ from CloudSat retrievals by a factor of more than 10 , and that the model-model differences are as large as the differences between models and data.

[6] Here, we compare CloudSat CWC profiles with an analyses product and two GCMs, with emphasis on the cloud vertical structure in connection with large-scale parameters. The analyses product is from the Goddard Earth Observing System Model, Version 5 (GEOS5), and the two GCMs are the National Center for Atmospheric Research Community Atmosphere Model (CAM, Version 3.5) and the Geophysical Fluid Dynamics Laboratory Atmospheric Model (Version 2.1, AM2), similar to those given by Wyant et al. [2006] but with updated model physics. Different from the free-running NCAR CAM3 and GFDL AM2, GEOS5 is a data assimilation system, which incorporates observations of many meteorological variables (see section 2.2). However, GEOS5 does not assimilate cloud measurement, such as data from CloudSat or CALIPSO. Thus, comparison of cloud product from GEOS5 analyses with CloudSat demonstrates the performance of the data assimilation system in reproducing the cloud structure given constraints on the meteorological fields, while the comparison of CloudSat data with two GCMs provide useful information about our ability of representing clouds in models. In this paper, the intercom- 

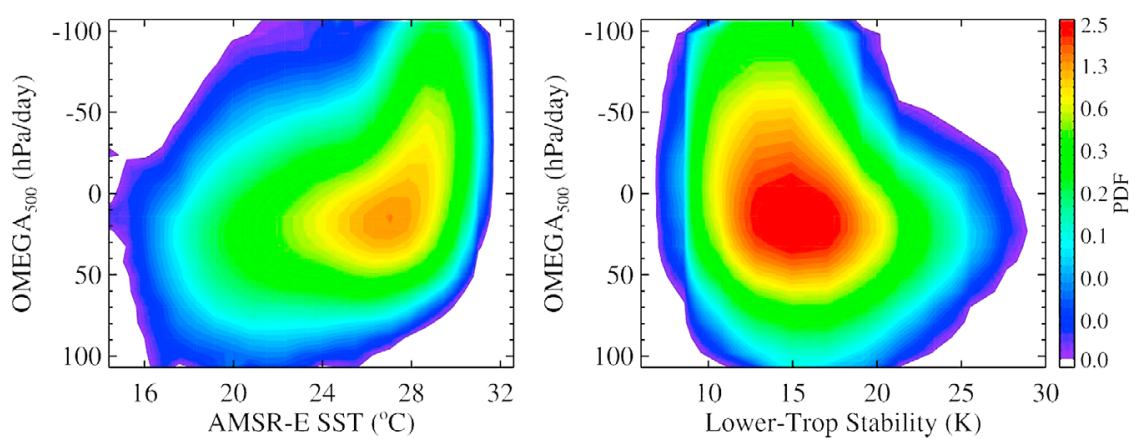

Figure 1. (left) Joint probability density function (PDF) of monthly mean vertical pressure velocity at $500 \mathrm{hPa}\left(\omega_{500}\right)$ from GEOS5 analyses and sea surface temperature (SST) from AMSR-E for all tropical grid boxes of $2.5^{\circ}$ (longitude) $\times 2.0^{\circ}$ (latitude) between $30^{\circ} \mathrm{S}$ and $30^{\circ} \mathrm{N}$. (right) Same as Figure 1 (left) except for $\omega_{500}$ and lower tropospheric stability (LTS) calculated from AIRS data.

parison is limited to CWC profiles due to space limit, although comparison of other cloud properties (such cloud fraction and cloud optical depth, etc) are as important as the CWC profiles and is deferred to future work.

[7] A step further from Wyant et al. [2006], we examine the CWC profiles sorted not only by $\omega_{500}$, but also by SST and LTS (defined as the potential temperature difference between $700 \mathrm{hPa}$ and $1000 \mathrm{hPa}$, i.e., LTS $\left.=\theta_{700}-\theta_{1000}\right)$. As $\omega_{500}$ represents the large-scale dynamic circulation regime, SST and LTS are indicative of thermodynamic factors that influence cloud formation and development. Although large-scale upward (downward) motions are generally associated with warm (cold) SST and low (high) LTS, the relationship of $\omega_{500}$ with SST or LTS is rather nonlinear. Shown in Figure 1 , the monthly mean $\omega_{500}$ over tropical $\left(30^{\circ} \mathrm{S}-30^{\circ} \mathrm{N}\right)$ grid boxes $\left(2.5^{\circ}\right.$ longitude $\times 2.0^{\circ}$ latitude $)$ from GEOS5 analyses for year 2007 is quite scattered with respect to SST (from AMSR-E) and LTS calculated from AIRS temperature data, with linear correlation coefficients of -0.062 and 0.015 , respectively. Thus, sorting CWC by SST or LTS is not a mere coordinate transformation from that sorted by $\omega_{500}$. Instead, they provide a multiperspective view of cloud dynamics and physics, which provides more information about cloud parameterizations in models than sorting by $\omega_{500}$ alone.

[8] As CloudSat retrieved CWC includes some contributions from precipitating particles, we separate the cloudy scenes with and without surface precipitation based on the precipitation flag in the CloudSat product. This provides a rough estimate of uncertainty for the discrepancies between model results and the retrieval. In this study, we are particularly interested in the relationships between cloud vertical structure and large-scale environmental conditions. Hence, the discussions about model-data differences are more focused on patterns, although quantitative differences are also noted.

[9] The structure of the paper is as follows. Section 2 describes the observations, the GEOS5 assimilation system, two GCMs, and the comparison strategy. Section 3 shows the comparison of observations and model results in geographical averages, as done conventionally. Section 4 presents the comparison of the regime-sorted cloud pro- files. Section 5 discusses the influence of precipitation on the L/IWC retrievals. Conclusions are given in section 6 .

\section{Observations, Models, and Approach}

\subsection{Observations}

[10] The CPR on CloudSat points in the nadir direction, with a nominal footprint of $2.5 \mathrm{~km}$ along track and $1.4 \mathrm{~km}$ cross track. The vertical resolution is approximately $480 \mathrm{~m}$, over sampled to $240 \mathrm{~m}$. Similar to other A-Train satellites, CloudSat provides two times of measurements each day, with equatorial crossing time around 0130 and 1330 LT.

[11] The CloudSat data products are downloaded from the CloudSat data processing center (http://cloudsat.cira. colostate.edu). The CloudSat L/IWC profiles are from the $2 \mathrm{~B}-\mathrm{CWC}-\mathrm{RO}$ (V4). The retrieval of L/IWC from RR is based on an optimal estimation algorithm: it retrieves parameters of cloud particle size distribution, and considers the temperature dependency of these parameters. The partition between liquid and ice clouds is based on temperature from the ECMWF analyses. For a temperature colder than $-20^{\circ} \mathrm{C}$, the cloud profile is considered pure ice and the IWC retrieval applies. For a temperature warmer than $0^{\circ} \mathrm{C}$, the cloud profile is assumed to be pure liquid and the $\mathrm{LWC}$ retrieval applies. In between $-20^{\circ} \mathrm{C}$ and $0^{\circ} \mathrm{C}$, the ice and liquid solutions are scaled linearly with temperature to obtain a smooth transition from all ice to all liquid while matching the radar measurements over the whole range. Due to the surface reflectance problem, CloudSat cannot accurately measure clouds in the lowest $1 \mathrm{~km}$ near the surface. So we limit our analysis to cloud profiles above $1 \mathrm{~km}$. Retrieval of LWC in heavily precipitating clouds may be contaminated by the precipitation signal and should be treated with caution. CloudSat also misses some thin cirrus clouds near the tropopause [Su et al., 2009; Haladay and Stephens, 2009]. Details about the L/IWC retrievals are described by Austin et al. [2009]. Another L/IWC retrieval (2B-CWC-RVOD), which uses combined radar reflectivity and visible optical depth from the Moderate Resolution Imaging Spectroradiometer (MODIS), differs from 2B-CWCRO less than $10 \%$ for IWC and within $30 \%$ for $\mathrm{LWC}$ (T. L'Ecuyer, personal communication, 2010). Wu et al. [2009] compared CloudSat and Aura Microwave Limb 
Sounder (MLS) IWC retrievals and found their relative differences within $50 \%$ over the range where the two instrument sensitivities overlap, but CloudSat R04 IWC generally is larger than MLS IWC in the upper troposphere about 14 $17 \mathrm{~km}$ altitudes. Eriksson et al. [2008] showed that the ice water paths (IWPs) from CloudSat, MODIS, the Advanced Microwave Sounding Unit-B (AMSU-B), MLS and OdinSMR (Sub-Millimeter Receiver) have substantial overlaps, but also significant disagreements for certain ranges of IWP. Large discrepancies also exist for CloudSat retrieved LWP from measurements by passive sensors (e.g., ISCCP, SSM/I and MODIS) [Li et al., 2008]. G. L. Stephens et al. (The character of low clouds over the Earth's oceans, submitted to Journal of the Atmospheric Sciences, 2010) showed that ECMWF and CAM3.6 simulated LWPs for cloudy scenes are significantly higher than the CloudSat counterpart, which may cause underestimate of low cloud optical depth feedback.

[12] For observed large-scale environmental data, we use $\omega_{500}$ from the 6-hourly GEOS5 analyses, SST from AMSR-E on Aqua, and LTS calculated from the AIRS temperature at $700 \mathrm{hPa}$ and $1000 \mathrm{hPa}$. The original grid sizes for $\omega_{500}$, SST, and atmospheric temperature data are $0.5^{\circ} \times 0.5^{\circ}, 0.25^{\circ} \times 0.25^{\circ}$ and $1^{\circ} \times 1^{\circ}$, respectively. All data are interpolated onto the CloudSat measurement locations and resampled to $2.5^{\circ}$ (longitude) $\times 2.0^{\circ}$ (latitude) grids for monthly means. For our analysis, 1 year of data in 2007 are used.

\subsection{The GEOS5 Analyses}

[13] The GEOS5 analyses are 6-hourly "snapshots" of the atmospheric state (surface pressure, temperature, zonal and meridional winds, moisture and ozone) produced daily at 0000, 0600, 1200, and 1800 UT using optimal combinations of model forecasts and many observations [Rienecker et al., 2008]. Observations including radiosondes and radiances from the Microwave Humidity Sounder (MHS), the Special Sensor Microwave/Imager (SSM/I) and the Atmospheric Infrared Sounder (AIRS), are fed into the GEOS5 momentum, temperature, moisture and ozone equations as additional forcing terms in $6 \mathrm{~h}$ segments that straddle the analysis times. The GEOS5 AGCM is coded flexibly, but used in particular configurations (spatial resolution and physical parameter settings) in each version of the assimilation system. Adiabatic transport is computed using the "finite volume dynamical core" [Lin, 2004] with a quasi-Lagrangian vertical coordinate, followed by remapping to the standard 72-layer hybrid grid on which physical tendencies are computed every $30 \mathrm{~min}$. The model includes prognostic equations for water vapor, liquid and ice water, and the subgrid convective contributions to L/IWC are parameterized. The Relaxed Arakawa-Schubert (RAS) convection code [Moorthi and Suarez, 1992] is used, with modifications based on Sud and Walker [1999] as described by Bacmeister et al. [2006]. RAS considers a sequence of detraining convective plumes extending between cloud base (set as a fixed layer in GEOS5, but inherently adaptable in RAS) and each layer below the tropopause region (close to $100 \mathrm{hPa}$ ); each plume produces detraining mass and cloud condensate at each layer and also modifies the environmental meteorological (temperature, moisture, wind) profiles felt by the next plume. The largescale cloud condensate scheme, based on probability density functions (PDFs) of the moisture assumed inside a grid box, incorporates changes to condensate and anvil clouds obtained from RAS, then computes new sources for the anvil cloud (freezing of existing condensate) and new partitioning of condensate, before computing the loss due to evaporation, autoconversion of liquid or mixed phase condensate, sedimentation of frozen condensate, and accretion of condensate by falling precipitation. Details of these processes are given by Rienecker et al. [2008]. The GEOS5 analyses for 2007 are used.

\subsection{Two GCMs}

[14] The model physical packages for the NCAR CAM3 and GFDL AM2 are similar to those described by Wyant et al. [2006, Table 1]. CAM3 is the Community Atmosphere Model version 3.5.50 [Collins et al., 2006] with modifications to the deep convective cloud parameterization described by Neale et al. [2008]. The updated cumulus scheme considers convective entrainment and convective momentum transport. A new two-moment stratiform microphysics is also included [Gettelman et al., 2008]. The GFDL AM2 used in this study is the version am2p14, which employs a finite volume dynamic core [Lin, 2004] and thus has more accurate dynamic transport than previous versions. The subgrid cumulus parameterization schemes are the same as those described by Global Atmospheric Model Development Team [2004] and listed by Wyant et al. [2006]. For CAM3 and AM2, the model versions that we use are in between the ones used for the IPCC Fourth Assessment Report (AR4) and the upcoming Fifth Assessment Report (AR5). One year simulations driven by prescribed SST are analyzed. The CAM3 is driven by seasonally varying climatological (30 year mean) SST and 1 year output is analyzed. The AM2 is forced by observed SST from 1979 to 2007, and the output for October 2006 to September 2007 is used in this analysis. For CAM3 and AM2, 6-hourly instantaneous snapshots are used. In CAM3 and AM2, L/IWC amounts include only floating liquid and ice cloud particles, while precipitating cloud particles are treated as separate variables (i.e., rain and snow mixing ratios or fluxes). The caveat of such separation for model-data comparison is discussed in section 5 .

\subsection{Comparison Strategy}

[15] As CloudSat observes clouds at two local times only, we interpolate 6-hourly model outputs on these two local times and construct monthly means from the interpolated results. We also resample all model results on the same $2.5^{\circ} \times 2.0^{\circ}$ grids. Previous studies [e.g., Li et al., 2007; Su et al., 2006] have shown that such temporal interpolation is important to reduce the model-data difference due to incomplete sampling of the diurnal cycle by satellite instruments. The monthly mean cloud amounts between the interpolated and uninterpolated model results can differ more than a factor of two, especially over land. The conditional sampling is performed on the monthly mean gridded data after interpolation.

[16] As CloudSat data have finer vertical resolution than models, we use each model's native vertical levels for illustration so as to maintain the vertical stratification of clouds represented in each model. To display CloudSat data in similar pressure coordinates, we use the GEOS5 geopotential height and pressure level correspondence to convert 

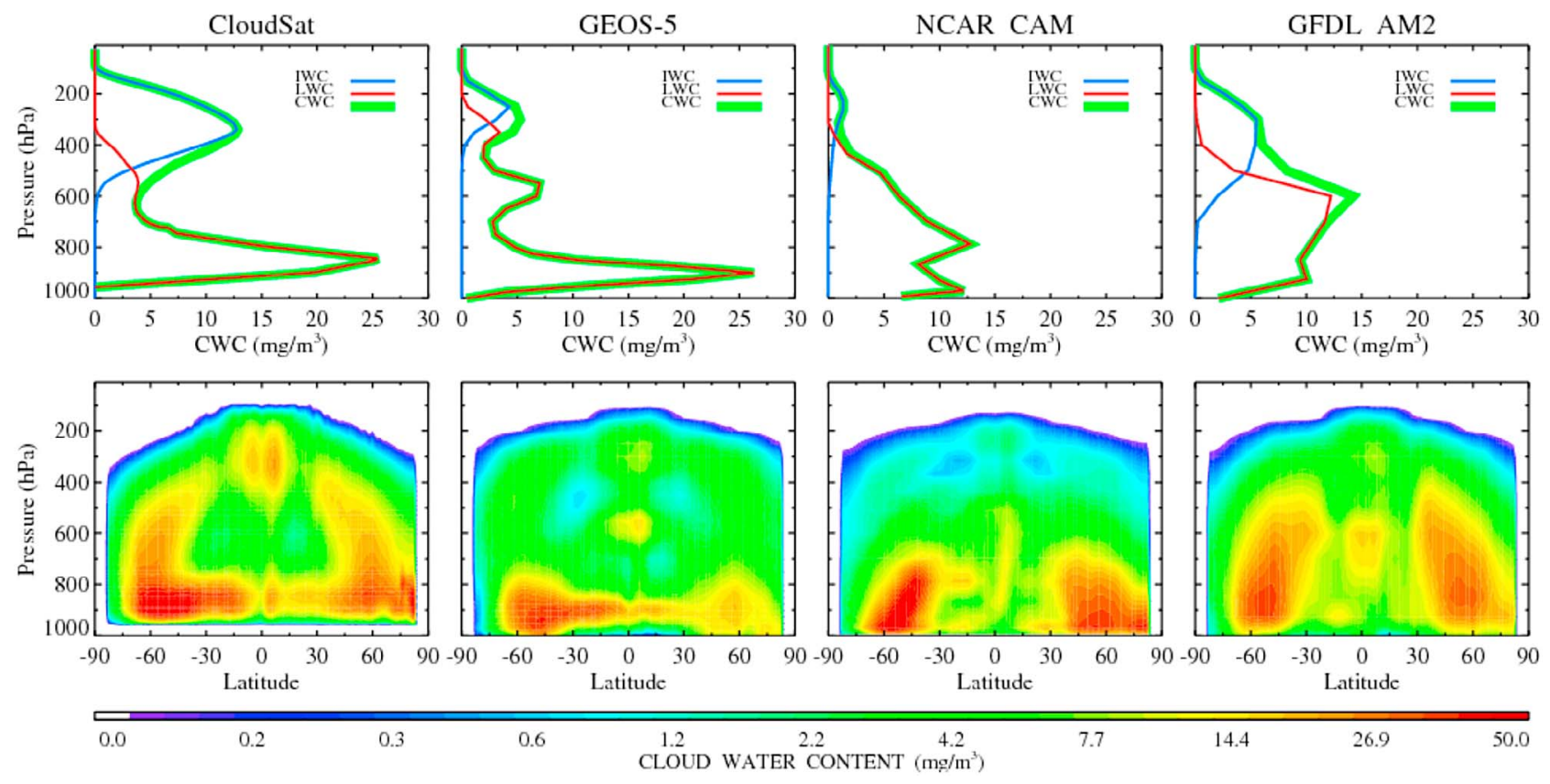

Figure 2. (top) Tropical-averaged and (bottom) zonal-averaged annual mean cloud water content (CWC) profiles from CloudSat and three model simulations.

the geometric heights in the original CloudSat product to pressure levels.

[17] When sorting the cloud profiles by $\omega_{500}$, SST and LTS, we use constant bin width over the reasonable ranges of large-scale parameters. The PDFs of each bin value are shown simultaneously. This is different from the stretched bin width used by Wyant et al. [2006], where each bin has the same occurrence frequency. The display using constant bin width with corresponding PDFs facilitates the modeldata comparison, since the differences in the observed and modeled PDFs of large-scale parameters are explicitly shown, helping understand the differences in observed and simulated clouds.

\section{Geographical Averages}

[18] We start with examination of conventional geographical averages. For the tropics $\left(30^{\circ} \mathrm{S}-30^{\circ} \mathrm{N}\right)$, the vertical profile of annual mean CWC from CloudSat shows two distinct peaks, one around $850 \mathrm{hPa}(1.5 \mathrm{~km})$ and the other around $350 \mathrm{hPa}(8 \mathrm{~km})$ (Figure 2, top). A secondary peak in LWC appears in the middle troposphere around $600-550 \mathrm{hPa}$, weakly indicative of middle-level congestus. Between 600 and $400 \mathrm{hPa}$, both liquid and ice particles exist, suggesting the presence of mixed phase clouds. The retrieval of mixed phase clouds is difficult [Zhang et al., 2010]; therefore, the CWC amount over this layer may carry a large uncertainty. The GEOS5 analyses and two GCMs produce less cloud ice in the upper troposphere (UT) than CloudSat, partly because CloudSat IWC may include contributions from precipitating snow (see discussion in section 5). GEOS5 and CAM3 IWC peak around $250 \mathrm{hPa}$, while AM2 has a broad layer of ice clouds from $700 \mathrm{hPa}$ to $100 \mathrm{hPa}$, with a peak around $300 \mathrm{hPa}$. Its IWC is also greater than GEOS5 and CAM3.
CAM3 produces the least IWC in the UT, less than $10 \%$ of CloudSat retrieval. For example, at $300 \mathrm{hPa}$, the tropical mean IWCs (LWCs) are 12.5 (0.006), 3.1 (2.2), 0.9 (0.006), and $5.5(0.1) \mathrm{mg} / \mathrm{m}^{3}$ for CloudSat, GEOS5, CAM3 and $\mathrm{AM} 2$, respectively. The tropical mean $\left(30^{\circ} \mathrm{S}-30^{\circ} \mathrm{N}\right)$ IWP for CloudSat, GEOS5, CAM3 and AM2 are 74.1, 16.0, 6.9, and $40.0 \mathrm{~g} / \mathrm{m}^{2}$, respectively.

[19] In the middle troposphere (500-600 hPa), the GEOS5 analyses and two GCMs produce larger CWC (primarily liquid) than CloudSat, with the largest value in AM2 ( $200 \%$ of CloudSat value). The GEOS5 LWC has three maxima (boundary layer, middle troposphere and UT) with decreasing amplitudes with height, while the other two models' LWC exhibits a broad maximum in the lower troposphere (LT) and a monotonic decrease above $600 \mathrm{hPa}$.

[20] In the boundary layer, GEOS5 displays the closest similarity to CloudSat, with its peak LWC around $900 \mathrm{hPa}$ (slightly lower than CloudSat) and a similar magnitude of around $25 \mathrm{mg} / \mathrm{m}^{3}$. In contrast, the magnitudes of $900 \mathrm{hPa}$ LWC in CAM3 and AM2 are approximately half of GEOS5 and CloudSat. Because CAM3 and AM2 have a rather broad liquid cloud layer in the lower and middle troposphere, their tropical mean LWPs are 50.9 and $56.2 \mathrm{~g} / \mathrm{m}^{2}$, respectively, slightly larger than CloudSat $\left(49.7 \mathrm{~g} / \mathrm{m}^{2}\right)$. GEOS5 liquid clouds extend high in the UT (above $400 \mathrm{hPa}$ ). Thus, the tropical mean LWP for GEOS5 is $51.3 \mathrm{~g} / \mathrm{m}^{2}$, also larger than CloudSat. If we restrict the LWPs to the lowest $2.5 \mathrm{~km}$, the corresponding modeled values are $25.7,25.1$, and $21.9 \mathrm{~g} / \mathrm{m}^{2}$ in GEOS5, CAM3 and AM2, respectively, all smaller than the CloudSat counterpart $\left(35.4 \mathrm{~g} / \mathrm{m}^{2}\right)$. The LWP values here are much smaller than the LWPs given by Stephens et al. (submitted manuscript, 2010), as the latter refers to the LWPs averaged over global oceanic cloudy scenes only, and our 


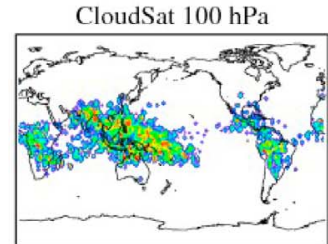

CloudSat $300 \mathrm{hPa}$

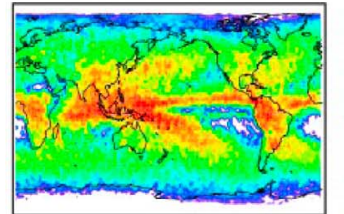

CloudSat $600 \mathrm{hPa}$

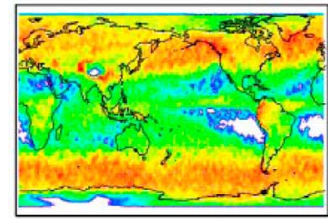

CloudSat $900 \mathrm{hPa}$

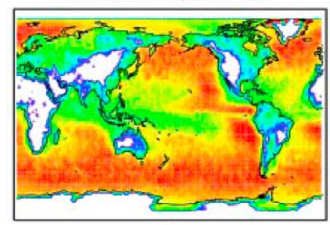

GEOS-5 $100 \mathrm{hPa}$

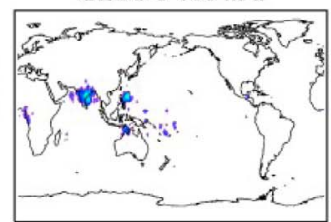

GEOS-5 $300 \mathrm{hPa}$

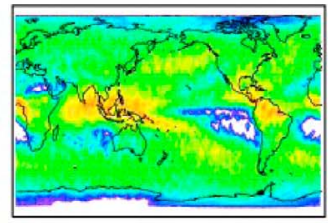

GEOS-5 $600 \mathrm{hPa}$

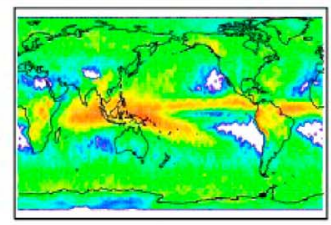

GEOS-5 $900 \mathrm{hPa}$

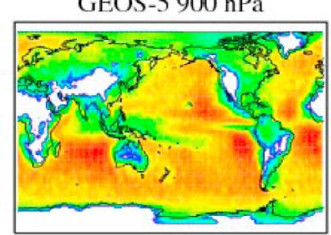

NCAR CAM $100 \mathrm{hPa}$

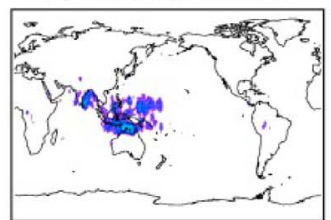

NCAR CAM 300 hPa

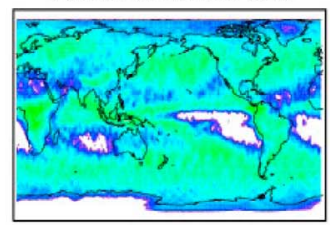

NCAR CAM $600 \mathrm{hPa}$

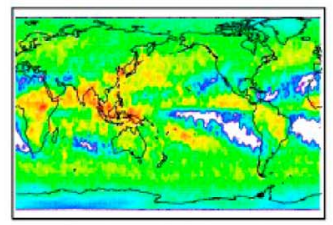

NCAR CAM $900 \mathrm{hPa}$

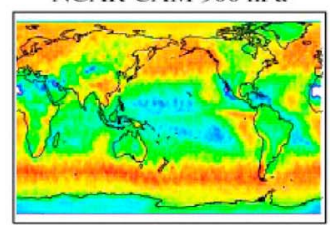

GFDL AM2 $100 \mathrm{hPa}$

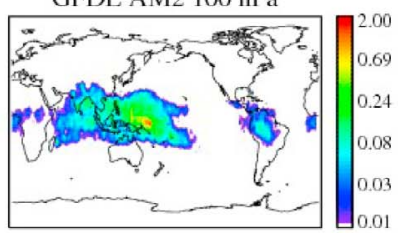

GFDL AM2 $300 \mathrm{hPa}$

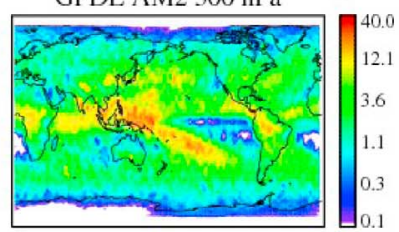

GFDL AM2 $600 \mathrm{hPa}$

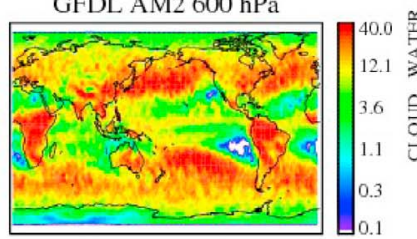

GFDL AM2 $900 \mathrm{hPa}$

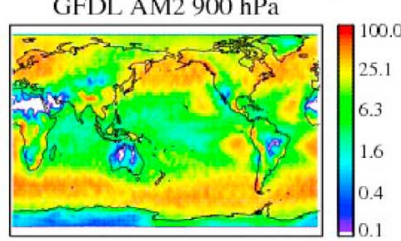

Figure 3. Horizontal maps of annual mean $\mathrm{CWC}$ at $900 \mathrm{hPa}, 600 \mathrm{hPa}, 300 \mathrm{hPa}$, and $100 \mathrm{hPa}$ for CloudSat and three model simulations.

values include both tropical cloudy and clear-sky scenes in the gridded means, regardless of land and ocean.

[21] Examining the latitudinal distribution of annual mean zonal mean CWC profiles (Figure 2, bottom), more modelobservation differences are disclosed. In the tropics, more cloud ice occurs in the Northern Hemisphere (NH) than in the Southern Hemisphere (SH), which is captured by all models, despite that models underestimate the amount of IWC. In the tropics, the simulated middle-level clouds have a rather different vertical structure among the three models, while the midlevel CWC magnitude is much reduced in the CloudSat retrieval. The CloudSat LWC in the tropics indicates an asymmetry between the $\mathrm{NH}$ and the $\mathrm{SH}$, with larger LWC in the SH. This feature is approximately reproduced in GEOS5 and AM2, but less pronounced in CAM3. In the middle and high latitudes, large CWC values extend beyond the melting level into the UT (mainly ice) in CloudSat and AM2, while the GEOS5 and CAM3 CWC are more confined below $600-800 \mathrm{hPa}$ (mainly liquid). CloudSat and GEOS5 exhibit peak CWC in the boundary layer in the tropics, which is almost absent in the two GCMs.

[22] We further compare the horizontal maps of annual mean CWC at four pressure levels (Figure 3). At $900 \mathrm{hPa}$, clouds are pervasive over the west coast of California, Peru, and Namibia, Northern Pacific and Atlantic, and the entire southern oceans, consistent with the climatology of stratus clouds [Klein and Hartmann, 1993]. GEOS5 approximately captures the distribution of stratus decks, with somewhat weaker magnitudes than CloudSat. As $850 \mathrm{hPa}$ where CloudSat LWC reaches a maximum in height, the GEOS5
LWC is about $35 \%$ of the CloudSat values (not shown). CAM3 and AM2 produce some low clouds in the climatological stratus regions, but the areal coverage is much less and the LWC magnitude is only $20-30 \%$ of the CloudSat retrieval.

[23] At $600 \mathrm{hPa}$, the cloud distribution shows a large discrepancy between the CloudSat retrieval and other outputs. As mentioned earlier, the retrieval of $\mathrm{CWC}$ has the most difficulty around the melting level, where mixed phase clouds prevail. Over the western Pacific and Indonesia, equatorial Pacific and Atlantic, CloudSat shows a weak hint of middle-level clouds while GEOS5 produces significant amounts of CWC. CAM3 and AM2 also have noticeable middle-level clouds, with higher magnitude in AM2. Over Africa and South America, the CWC amount is approximately similar among CloudSat, GEOS5 and CAM3, but $\mathrm{AM} 2$ has very large values. AM2 also produces large CWC in the midlatitude storm tracks, somewhat similar to CloudSat, but GEOS5 and CAM3 fail to reproduce it, consistent with zonal means shown in Figure 2 (bottom).

[24] Despite the fact that the amount of IWC is much smaller in the analyses and GCMs than in CloudSat, the spatial distribution of ice clouds is approximately consistent among all of them. High IWC occurs over the climatologically deep convective regions (the western Pacific, the Indian Ocean, equatorial Pacific and Atlantic, central African and South America). The intertropical convergence zone (ITCZ) is weak in terms of IWC in the model results. CAM3 produces the least amount of IWC at $300 \mathrm{hPa}$ among the three model outputs. AM2 has the closest match to the 
CloudSat IWC, although the AM2 IWC is only about $50 \%$ of the CloudSat value. At $100 \mathrm{hPa}$, GEOS5 yields the least amount of cloud ice, while AM2 compares reasonably well to CloudSat with a somewhat smaller magnitude.

\section{Regime-Sorted Cloud Profiles}

\subsection{Sorting by $\omega_{\mathbf{5 0 0}}$}

[25] Since $\omega_{500}$ is a good and simple proxy for large-scale atmospheric circulation, we first sort the monthly mean CWC profiles by $\omega_{500}$ to delineate the relationship between cloud vertical structure and large-scale dynamical regime. In Figure 4 , the PDFs of $\omega_{500}$ among all models are fairly similar with a peak close to $20 \mathrm{hPa} / \mathrm{d}$ associated with climatologically mean radiative cooling. Note that the PDFs pertain to the $\omega_{500}$ values where CloudSat has overpasses. Since a full year of data is used, such PDFs are close to the actual PDFs of $\omega_{500}$ over the entire tropical grids. The separation of high and low clouds in large-scale ascending and descending regimes is striking in the CloudSat CWC, as shown by Su et al. [2008], which used instantaneous data along the CloudSat tracks. In the ascending regime, there appears to be a small amount of middle-level clouds around 500-600 hPa (see Figure 4, middle). GEOS5 produces a clear trimodal cloud structure: the low clouds spread over the subsidence regime with less vertical extent than CloudSat, while the high and middle clouds concentrate in the ascending regime. The GEOS5 high clouds consist of similar amounts of ice and liquid, but its middle level clouds are only of liquid phase. For CAM3 and AM2, there is a clear clustering of clouds (primarily liquid) in the middle levels associated with large-scale upwelling. The low clouds are scattered in the subsidence regime, with variable heights. CAM3 shows two layers of boundary layer clouds, one near the surface and one around $800 \mathrm{hPa}$ (which occurs primarily in the Southern Hemispheric subtropics), with the higher layer corresponding to greater subsidence rate, which is counterintuitive given the connection between $\omega_{500}$ and boundary layer height. Overall, both CAM3 and AM2 do not reproduce low clouds in a realistic way in the large-scale descending regime. The better agreement with CloudSat low clouds in GEOS5 analyses may be an indication of the improved modeling skill by data assimilation, even though the assimilation operates only on dynamic and thermodynamic state variables, not clouds themselves.

[26] For ice clouds, the correspondence of large IWC to strong upward motion is captured by all models. However, AM2 seems to have a very broad ice cloud layer in the vertical, with some ice clouds extending over the subsidence regime.

\subsection{Sorting by SST}

[27] Figure 5 shows the CWC profiles sorted by SST and Figure 6 shows CWC as a joint function of $\omega_{500}$ and SST. The AMSR-E SST is used to sort CloudSat CWC while each model uses its own SST output. The normalized joint occurrence frequency of $\omega_{500}$ and SST are shown in black contours in Figure 6. We find that the joint distributions of $\omega_{500}$ and SST are similar (Figure 6), suggesting that the analyses model and GCMs reasonably reproduce the relationship between large-scale circulation and SST on monthly and annual mean time scales, although the agreement on shorter time scales might not be as good, which may contribute to the differences in regime-sorted cloud distributions. We note that the effects of dynamic (e.g., $\left.\omega_{500}\right)$ and thermodynamic factors (e.g., SST) enter the cloud parameterizations in an indirect way. In our discussions, we use the term "high (or low) sensitivity" to qualitatively describe the role of each large-scale parameter in determining cloud amounts.

[28] For CloudSat CWC, the grouping of high (low) clouds in warm (cold) SST regions is fairly similar to that in the domain of $\omega_{500}$ considering a rough mapping of $\omega_{500}$ to SST (Figure 5). The largest values of LWC in the boundary layer occur at SST around $18^{\circ}-20^{\circ} \mathrm{C}$. However, the model simulated CWCs sorted by SST show quite different characteristics from those sorted by $\omega_{500}$, especially in CAM3 and AM2. The GEOS5 simulated low clouds are widespread in the regions of SST $<28^{\circ} \mathrm{C}$, and there appears to be an increase of cloud top height with increasing SST (Figure 5), while increasing upward velocity is not obviously accompanied by increasing stratiform cloud top height. For CAM3 and AM2, large LWCs occur in the lower troposphere over relatively cold SST, while high concentration of low clouds is less outstanding in the subsidence regime in Figure 4, suggesting CAM3 and AM2 low cloud formation is more sensitive to SST and less sensitive to subsidence rate. In CAM3, the two discrete layers of low clouds discussed before correspond to different ranges of SST (below $24^{\circ} \mathrm{C}$ and between $24^{\circ} \mathrm{C}$ and $27^{\circ} \mathrm{C}$ ), with higher cloud top over warmer water. The low clouds in AM2 are concentrated over the SST values between $17^{\circ} \mathrm{C}$ and $25^{\circ} \mathrm{C}$.

[29] Not only the model produced low clouds exhibit varying features in the domain of SST and $\omega_{500}$ (Figures 4 and 5), the model generated middle level clouds also appear differently as a function of SST from that of $\omega_{500}$. In Figure 5, the middle level clouds in CAM3 and AM2 are barely discernible over warm SST, while they are predominant in the ascending regime (Figure 4). Hence, we infer that the middle level clouds parameterized in CAM3 and AM2 are primarily controlled by updraft speed, and rather insensitive to SST. This is further illustrated in Figure 6 (middle) as discussed later.

[30] For high clouds, if we ignore the fact that the modeled IWC is much weaker than the CloudSat retrieval, the association of relatively high IWC with warm SST in the analyses and GCMs is consistent with the observed, suggesting that the parameterization of deep convection is fairly sensitive to SST in these models. Regions with strong largescale ascent and warm sea surface are mostly conducive to deep convection. For AM2, significant ice cloud formation occurs at fairly low altitude $(\sim 700 \mathrm{hPa})$ in both $\omega_{500}$ and SST sorted CWCs, indicating that AM2 tends to generate ice at relatively warm temperature compared to other models and CloudSat.

[31] When CWC is displayed as a joint function of $\omega_{500}$ and SST (Figure 6), the coupled control of dynamics and thermodynamics on clouds can be shown. We call this type of analysis as bivariate composite (BVC), since two parameters are used to describe the variations of a dependent variable. In Figure 6, three levels of CWC $(300 \mathrm{hPa}, 600 \mathrm{hPa}$ and $900 \mathrm{hPa}$ ) are shown in color shadings, representing high, middle and low level clouds. Note the color scale for CWC is the same as in Figures 4 and 5, making it easy to compare values of CWC in different functional spaces. The 


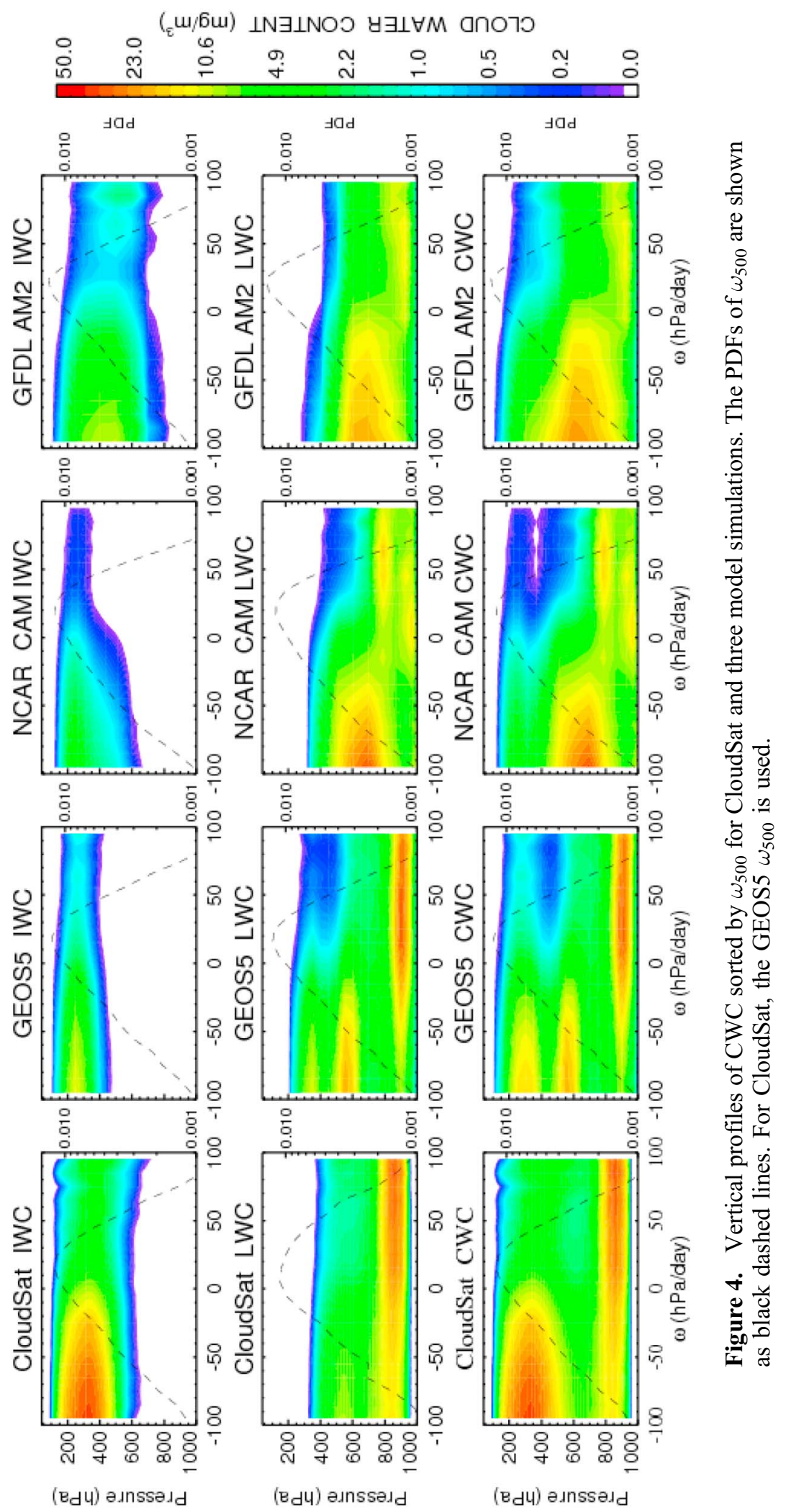




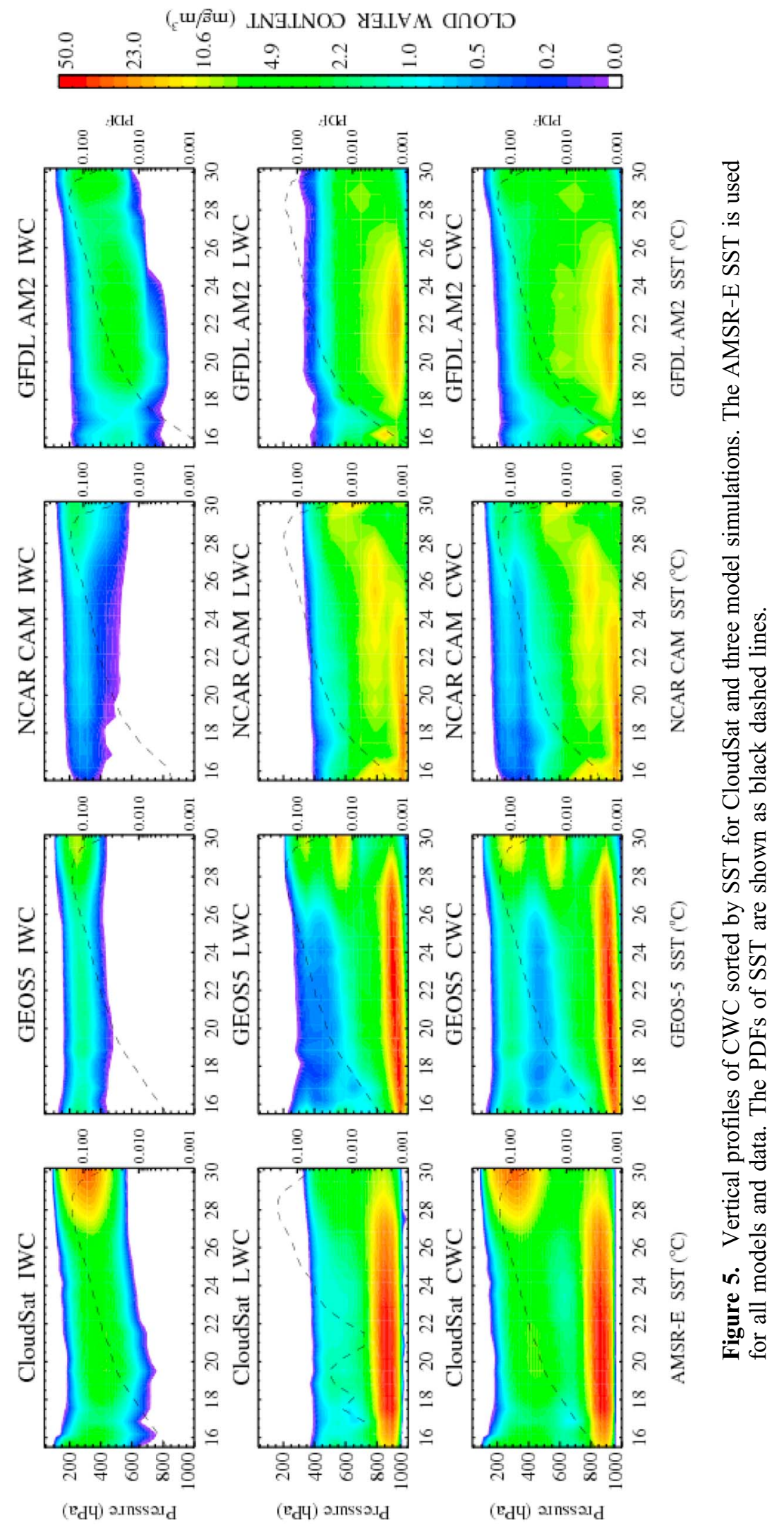




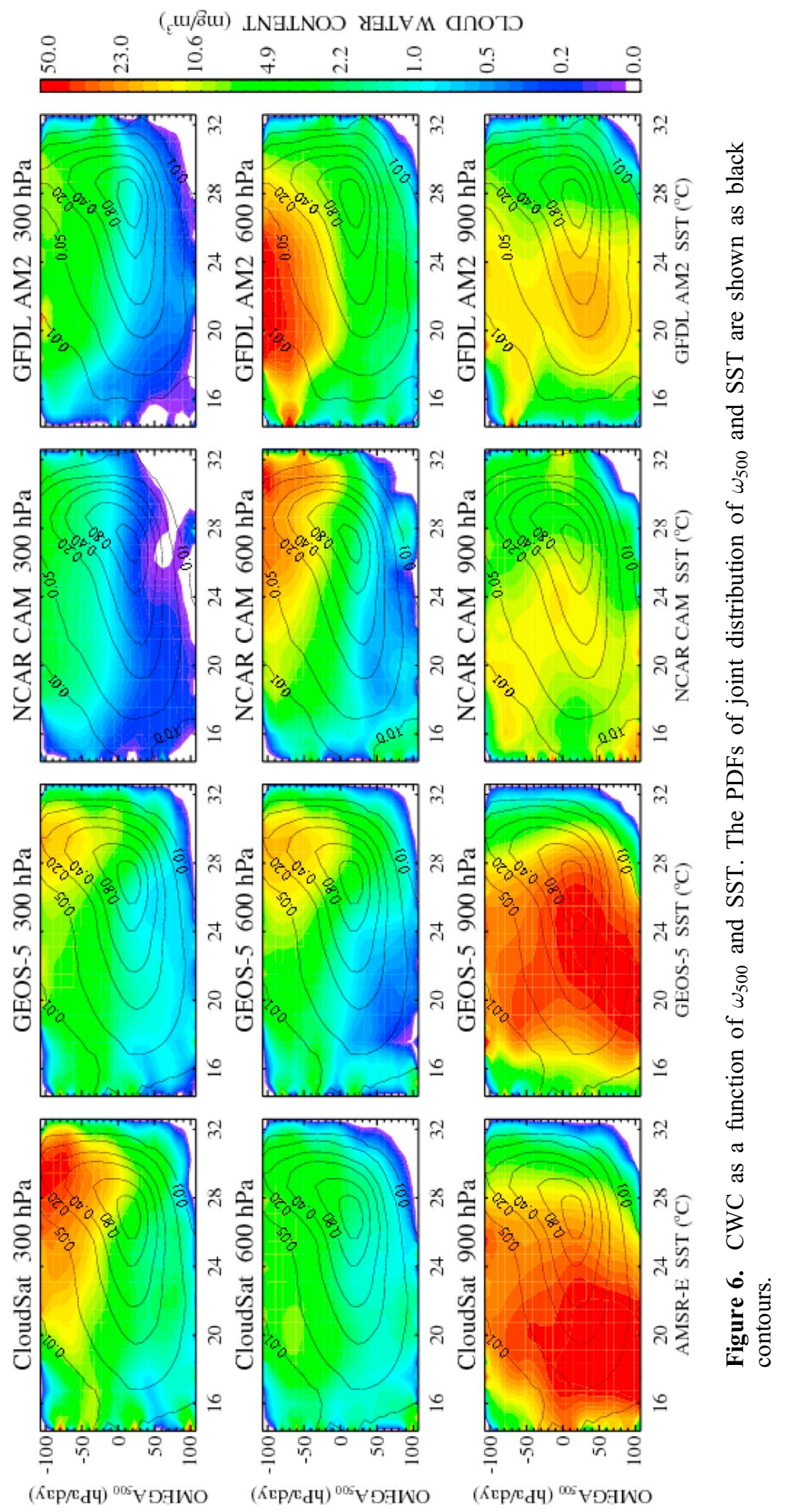


preference of large amounts of cloud ice in regions of largescale upwelling and warm SST is qualitatively similar in observations and model outputs, but CAM3 and AM2 have less variation of $300 \mathrm{hPa}$ IWC with SST than CloudSat and GEOS5 analyses. The large CWCs at $600 \mathrm{hPa}$ for three model outputs are concentrated over strong upwelling regimes $\left(\omega_{500}<-50 \mathrm{hPa} / \mathrm{d}\right)$, while the corresponding SST values span quite different ranges: $26^{\circ}-30^{\circ} \mathrm{C}$ for GEOS5, $24^{\circ}-32^{\circ} \mathrm{C}$ for $\mathrm{CAM} 3$ and $18^{\circ}-28^{\circ} \mathrm{C}$ for $\mathrm{AM} 2$, although the joint PDFs of $\omega_{500}$ and SST (the black contours) are similar among the models. This suggests that the parameterizations for middle clouds have similar dependence on vertical velocity, but different sensitivity to SST values. As the large $600 \mathrm{hPa}$ CWC in CAM3 and AM2 do not align with the peak PDFs of joint $\omega_{500}$ and SST, i.e., their occurrence is fairly low (especially in AM2), when CWC is sampled on SST, the clustering of middle clouds is nearly absent. CloudSat retrieval of CWC around the melting level is problematic, as mentioned earlier, but the disagreements among the models indicate that improvement for the parameterizations of middle-level convection is needed. For low clouds, both GEOS5 and CloudSat show large CWC over a broad range of $\omega_{500}$ and SST less than $28^{\circ} \mathrm{C}$, with larger CWC over stronger subsidence $\left(\omega_{500}>50 \mathrm{hPa} / \mathrm{d}\right)$ and SST between $16^{\circ} \mathrm{C}$ and $24^{\circ} \mathrm{C}$. However, CAM3 shows a peak $900 \mathrm{hPa}$ CWC near zero $\omega_{500}$ and $24^{\circ} \mathrm{C} \mathrm{SST}$, and another (possibly pathological) peak in the upwelling regime and cold SST $\left(<20^{\circ} \mathrm{C}\right)$. In AM2, the peak $900 \mathrm{hPa} \mathrm{CWC}$ occurs around $50 \mathrm{hPa} / \mathrm{d}$ of $\omega_{500}$ and between $20^{\circ} \mathrm{C}$ and $24^{\circ} \mathrm{C} \mathrm{SST}$. Both CAM3 and AM2 have much weaker magnitude in $900 \mathrm{hPa}$ CWC than CloudSat and GEOS5. Again, the relatively better performance of GEOS5 analyses, compared to the other two GCMs, may indicate the constraints placed on the large-scale state variables (temperature, moisture and winds) by data assimilation tend to yield better simulation of clouds.

\subsection{Sorting by LTS}

[32] LTS is defined as the potential temperature difference between $700 \mathrm{hPa}$ and $1000 \mathrm{hPa}$. It is particularly relevant for the stratiform cloud amount [Klein and Hartmann, 1993]. Although LTS is related to SST, as surface air temperature closely follows SST, LTS depends on the temperature profile in the boundary layer. Thus, sorting clouds by LTS provides additional information besides sorting clouds by SST. The stratus parameterization in CAM3 is based on the work of Klein and Hartmann [1993] in which LTS is a key factor for low cloudiness. Figure 7 shows the LTS-sorted CWC profiles and Figure 8 shows the BVC of CWC as a function of $\omega_{500}$ and LTS. For CloudSat, AIRS temperature was used to calculate the potential temperature $(\theta)$ at $700 \mathrm{hPa}$ and $1000 \mathrm{hPa}$. For each model, the respective temperature profiles were used to calculate LTS.

[33] When sorted by LTS, CloudSat low clouds are highly concentrated over LTS greater than $15 \mathrm{~K}$, and there is a tendency of decreasing cloud top with increasing LTS. Such feature is approximately captured by GEOS5 analyses with somewhat lower cloud tops. For CAM3 and AM2, the low clouds exhibit a higher degree of "concentration" in the domain of LTS than in the domain of SST and $\omega_{500}$. Large LWC occurs over the LTS values of $15-30 \mathrm{~K}$ in CAM3 and
$15-20 \mathrm{~K}$ in AM2. LTS less than $15 \mathrm{~K}$ may be a rough threshold for the onset of deep convection in the models.

[34] The middle-level clouds (mainly liquid) are evident in LTS-sorted CWC profiles for GEOS5 and CAM3, but less pronounced in CloudSat and AM2 counterparts, although AM2 middle-level clouds are conspicuous in the domain of $\omega_{500}$. Again, the different characteristics of regime-sorted CWC profiles suggest that the cloud parameterizations in CAM3 and AM2 respond to dynamic and thermodynamic factors differently: for low clouds, boundary layer stability and thermal condition (i.e., LTS and SST) are more controlling than midtropospheric vertical velocity, while the upwelling strength is more correlated with middle level clouds than with low level clouds.

[35] For high clouds, the analyses and two GCMs show large IWCs occur in the regions of relatively low LTS, consistent with CloudSat observation. LTS less than $15 \mathrm{~K}$ seems to be a rough threshold for the onset of deep convection.

[36] Moreover, we find that the PDFs of LTS from AIRS observation and model outputs exhibit some noticeable differences, especially in skewness, which may also contribute to the simulated cloud differences. The observed LTS based on AIRS data has a broader distribution than the analyses data and two model simulations. GEOS5 assimilation rarely produces LTS $<9 \mathrm{~K}$, as only AIRS radiance is assimilated but not AIRS retrievals. CAM3 and AM2 LTSs rarely exceed $28 \mathrm{~K}$. Hence, the observed clouds occur over a greater range of LTS than the model results.

[37] The BVCs of CWC as a joint function of $\omega_{500}$ and LTS show that ice clouds are preferentially over upwelling and low LTS regimes, with much smaller magnitudes in the models than CloudSat. At $600 \mathrm{hPa}$, the lack of CWC clustering in the CloudSat data is expected due to the difficulty in retrieving mixed phase clouds, while model outputs show peak CWC in the upwelling and relative low LTS values. AM2 produces the largest $\mathrm{CWC}$ at $600 \mathrm{hPa}$ than other models and the peak CWC spreads over LTS from 10 to $20 \mathrm{~K}$, qualitatively resembling the BVCs by $\omega_{500}$ and SST (Figure 6). Again, we note that the peak $600 \mathrm{hPa} \mathrm{CWC}$ in AM2 does not correspond to the high occurrence frequency of joint $\omega_{500}$ and LTS, causing the rather weak concentration of middle clouds in the LTS-sorted CWC profile (Figure 7). At $900 \mathrm{hPa}$, CloudSat and GEOS5 liquid clouds are widespread over large-scale descending regime (including some weakly upwelling regime), but are essentially constrained by LTS $>10 \mathrm{~K}$. CAM3 and AM2 low clouds occur over a rather narrow range of LTS between 15 and $25 \mathrm{~K}$. Their low clouds association with $\omega_{500}$ is fairly weak, and somewhat opposite: in CAM3, the peak CWC occurs at negative $\omega_{500}$; but in AM2, the peak CWC occurs at positive $\omega_{500}$.

\section{Influence of Precipitation on Cloud Retrievals}

[38] The CloudSat radar is sensitive to both floating and falling hydrometers. The influence of precipitation on radar reflectivity and thus the CWC retrieval is inevitable. It is difficult to precisely quantify the contributions of floating and falling cloud particles to the retrieved CWC values. As the standard CWC product provides flags for precipitation, we attempt to coarsely assess the impact of precipitation on the $\mathrm{CWC}$ retrieval, thus on the model-data differences shown 

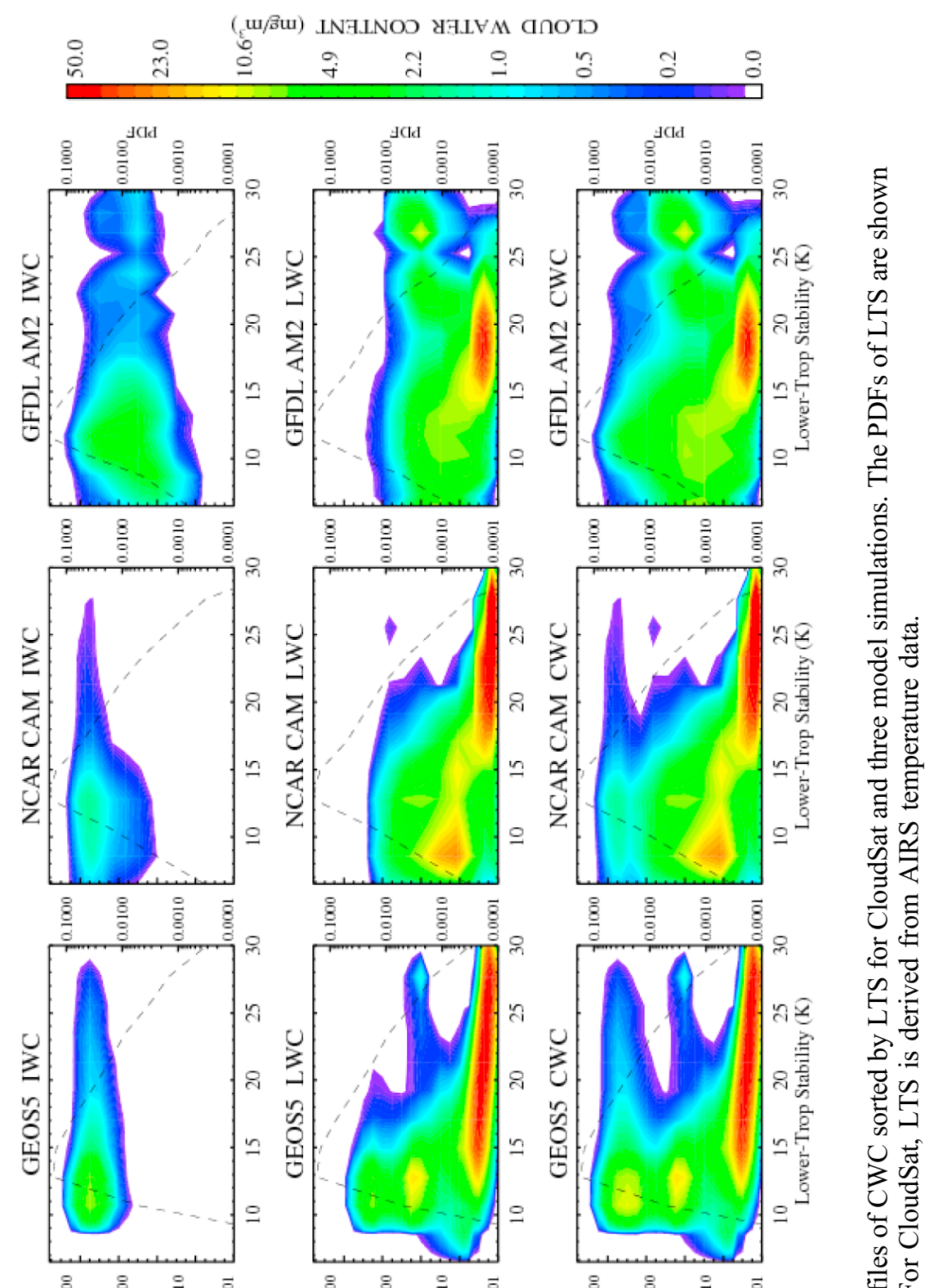

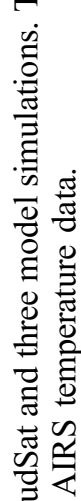
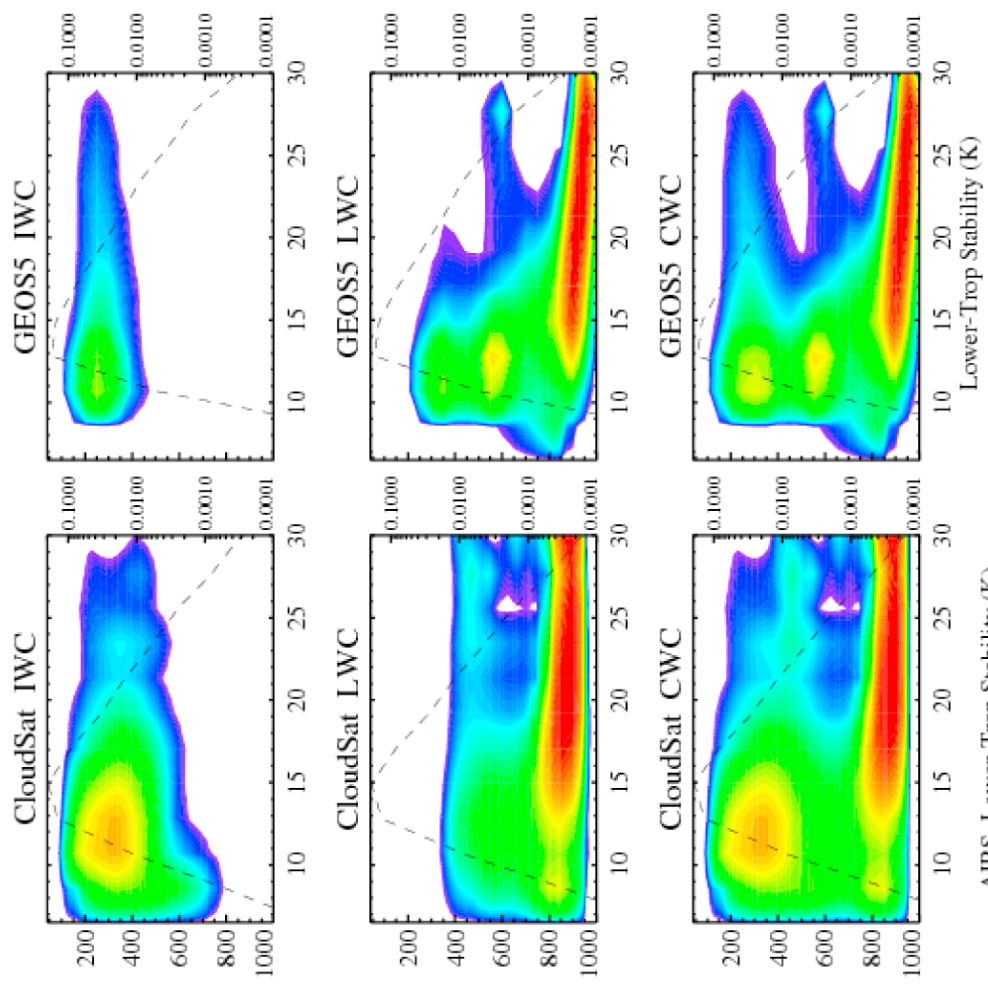

늠

迥

出.

西要

봉

造

훙
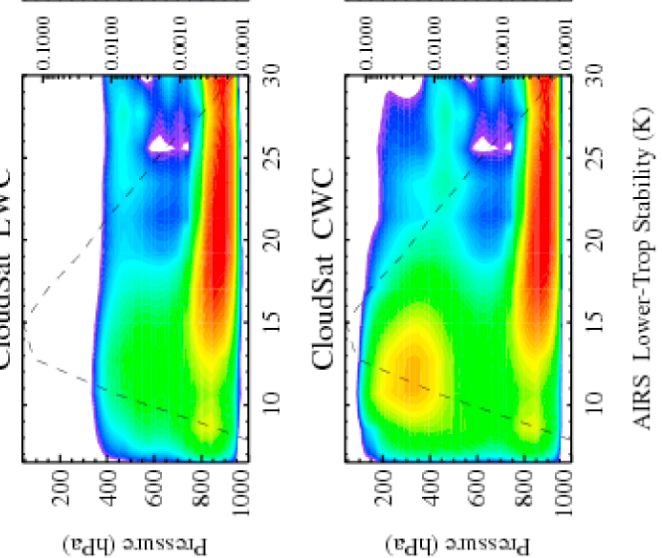

它

]ี

$>$ 过

$\therefore$

i 

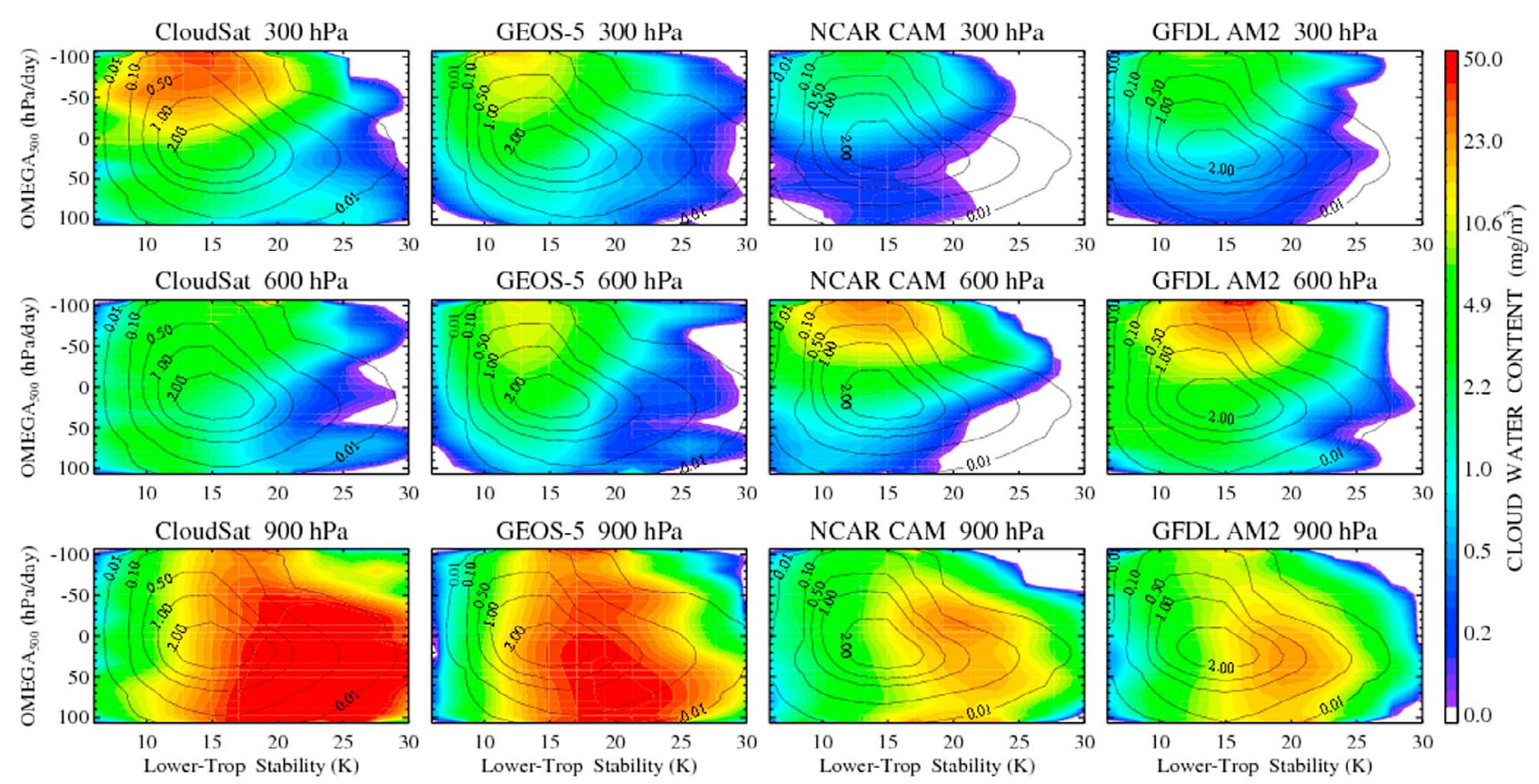

Figure 8. CWC as a function of $\omega_{500}$ and LTS. The PDFs of joint distribution of $\omega_{500}$ and LTS are shown as black contours.

earlier. Figure 9 shows the CWC profiles sorted by $\omega_{500}$, SST and LTS averaged for scenes without precipitation. The vertical stratification of clouds is similar to Figures 4,5 , and 7 , but the magnitudes differ significantly. For the scenes without surface precipitation (including clear-sky scenes), the averaged CWC is much smaller than the averages for all scenes. In Figure 9, at $300 \mathrm{hPa}$, the maximum IWC is $12.9 \mathrm{mg} / \mathrm{m}^{3}$, approximately $35 \%$ of the maximum IWC for all scenes regardless of precipitation in Figure 4. At $850 \mathrm{hPa}$, the maximum LWC is about $31.4 \mathrm{mg} / \mathrm{m}^{3}, \sim 80 \%$ of the all-scene average. In terms of tropical mean IWP and LWP, the nonprecipitating scenes account for 20.1 (ice) and 25.9 (liquid) $\mathrm{g} / \mathrm{m}^{2}$, about $27 \%$ and $52 \%$ of all-scene averages, respectively. Considering all vertical levels, the overestimate of CWC due to the precipitation interference is approximately a factor of 3-4 for ice clouds, and up to a factor of 2 for liquid clouds. Such estimates represent an approximate upper bound for the precipitation influence on the IWC and LWC retrieval. The actual cloud profiles may lie in between the averages for all scenes and nonprecipitating scenes.

[39] When compared to the model produced CWC, which pertains to floating particles only, it is not clear what fraction of the retrieved CWC directly corresponds to the modeled quantity, as the model grids are not entirely precipitation free. Combining the model produced rain and snow with liquid and ice cloud water content may bring closer the modeled and retrieved CWC. However, as the partition between the falling and floating particles in the models largely depends on cloud particle sizes, which are poorly constrained by observations, it is not clear what fraction of rain/snow should be included in liquid/ice cloud water content for a fair comparison with the CloudSat data. Continuous efforts have been made to partition CloudSat CWC retrieval into different scenes for comparison with models based on cloud classification, precipitation and particle size distribu- tion [e.g., Li et al., 2008; Waliser et al., 2009; W.-T. Chen et al., Partitioning CloudSat ice water content for comparison with upper tropospheric ice in global atmospheric models, submitted to Journal of Geophysical Research, 2010]. Nevertheless, since the model-data difference in CWC can be as large as a factor of 10 (for example, IWC in CAM3), the inclusion of precipitating particles in the CloudSat retrieval cannot fully explain the quantitative discrepancies between the model produced CWC and the observations.

\section{Conclusions}

[40] One year (2007) of CloudSat retrieved CWC profiles are compared with GEOS5 analyses, NCAR CAM3 and GFDL AM2 simulations, focusing on the tropics $\left(30^{\circ} \mathrm{S}-30^{\circ} \mathrm{N}\right)$. Instead of using standard monthly means from models, we have interpolated 6-hourly model outputs onto CloudSat measurement locations in both space and time, and reconstructed monthly averages at the same horizontal grid boxes for CloudSat, the analyses and two GCMs. Such interpolations reduce the sampling artifacts and ensure a fair comparison between satellite measurements and model results. We have examined both the geographical averages and the conditionally sampled cloud profiles by large-scale parameters, i.e., $\omega_{500}$, SST and LTS. We emphasize on identifying the different degree of sensitivity of model produced clouds in response to large-scale dynamic and thermodynamic factors, although attribution of model-data discrepancies to the specifics in the models' cloud parameterizations is beyond the scope of this study. In the three model products, the amounts of IWC in the UT and LWC in the boundary layer are much less than the CloudSat retrieval, while the amount of middle level clouds is greater than CloudSat in the tropics. Such biases are partly due to the problems in the CWC retrieval. 


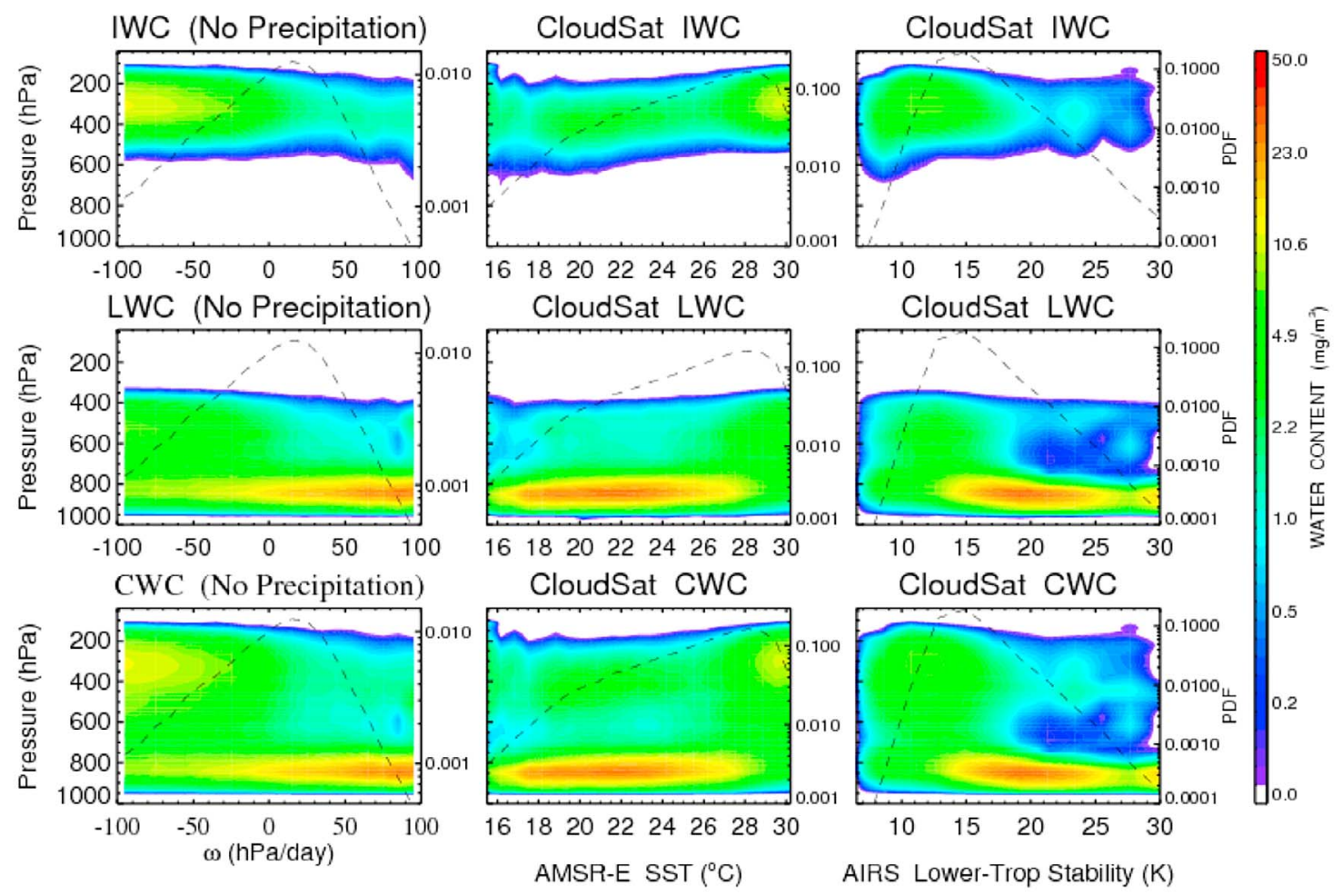

Figure 9. Vertical profiles of CloudSat CWC sorted by GEOS5 $\omega_{500}$, AMSR-E SST, and AIRS LTS averaged for nonprecipitating scenes.

The contribution of precipitating particles to the retrieved CWC is estimated to be approximately within a factor of $3-4$ for ice clouds and a factor of 2 for liquid clouds. Such magnitudes are comparable to the model-data discrepancies in some cases, but do not account for all the discrepancies, especially for ice clouds, for which the model-data differences are up to a factor of 10 . The underestimate of ice clouds in the models can significantly influence the simulated cloud radiative effects [Waliser et al., 2011]. Thus, improvements of the cloud parameterization schemes in the models are sorely needed. On the other hand, the CloudSat retrieval based on fixed temperature threshold for liquid and ice cloud phases may be also problematic.

[41] Regardless of the magnitude differences in CWC between the models and data, the vertical stratification of clouds and their association with the large-scale parameter regimes are strikingly different among the models and between the models and data. In general, the CWC profiles from the GEOS5 analyses have the closest match to CloudSat retrieval among the three models, especially for low clouds. This indicates that better constraints on the model's dynamic and thermodynamic variables may lead to better performance of cloud simulations. We note that we have used GEOS5 $\omega_{500}$ to sort CloudSat CWC. Thus, the difference in the $\omega_{500}$-sorted CWC between GEOS5 and CloudSat directly points to the problem of cloud schemes in the data assimilation model, while for CAM3 and AM2, the different $\omega_{500}$-sorted CWC from the observations may result from errors in both simulations of $\omega_{500}$ and cloud parameterizations. CAM3 is driven by climatological SST, instead of 2007 observed SST, which may be another factor that contributes to some model-data differences.
[42] For high clouds, the CloudSat large IWCs are preferentially distributed over large-scale ascending, warm SST $\left(>26^{\circ}-27^{\circ} \mathrm{C}\right)$ and low LTS $(<15 \mathrm{~K})$ regimes. Such characteristics are successfully captured in the analyses and GCMs, despite of the underestimate of IWC magnitudes. AM2 tends to produce ice at relatively low altitudes (warm temperature), which may not be realistic.

[43] For middle level clouds, little information can be extracted from the CloudSat data due to the difficulties in obtaining accurate retrieval around the melting level. The GEOS5 analyses and the two GCMs produce substantial middle level clouds associated with large-scale upwelling. In CAM3 and AM2, the middle level clouds are not evident in the domain of SST, and only marginally discernible in the domain of LTS, suggesting that the middle-level clouds in the models are primarily correlated to the dynamics and less sensitive to the boundary layer stability and thermal conditions. Improvement to the models' middle-level convection may pay attention to connection with boundary layer conditions.

[44] For low clouds in the boundary layer, large discrepancies exist between the model products and the observations, and among the model products. CloudSat low clouds are congregated in the regions of large-scale subsidence, SST $<27-28^{\circ} \mathrm{C}$ and LTS $>15 \mathrm{~K}$. In CloudSat and GEOS5 analyses, the cloud top height of stratiform clouds appears to increase with increasing SST, but less obviously changes with the subsidence rate. For CAM3 and AM2, there is a very weak clustering of low clouds in the $\omega_{500}$ domain but a clear congregation in the SST and LTS domains, while the latter is more or less by design of their low cloud parameterization schemes. The strong connection of low clouds 
with $\omega_{500}$ in CloudSat and GEOS5 indicates that dynamic factors (e.g., $\left.\omega_{500}\right)$ are coupled with thermodynamic factors in determining the low cloud amount. We speculate that strengthening the coupling of large-scale circulation with boundary layer stability may help to improve low cloud parameterizations. Although both CAM3 and AM2 capture some degree of low cloud clustering in the SST and LTS regimes, the ranges of SST and LTS values favorable for low clouds are narrower in the two models than those in CloudSat and GEOS5. In particular, CAM3 and AM2 low clouds are concentrated over LTS between 15 and $25 \mathrm{~K}$, while CloudSat and GEOS5 low clouds are spread over all LTS greater than $10 \mathrm{~K}$. Thus, CAM3 and AM2 generally have limited low clouds in the boundary layer compared to GEOS5 and CloudSat. This indicates another potential area for improvements of low cloud parameterization: to broaden the ranges of thermodynamic thresholds for low cloud formation.

[45] This paper serves as an exploratory study to innovatively utilize satellite observations for evaluations of model simulations and improvements of model physical parameterizations of clouds. Although the retrieved $\mathrm{CWC}$ values from CloudSat have large certainties, the vertical cloud distributions and connections with large-scale environmental conditions provide valuable new metrics for the modeling community. Through the conditional sampling approach, we identify the degree of sensitivity in modeled clouds to largescale dynamic and thermodynamic conditions. As the largescale parameters that we have explored here, i.e., $\omega_{500}$ and SST, are not directly built in the models' cloud parameterization schemes, the identification of specific parameters that can be adjusted in models' cloud schemes is not realized here. However, our analysis will guide future investigation to pinpoint the exact tunable parameters in the models in order to reproduce the observed clouds relations with large-scale environmental conditions. For example, the threshold value for the onset of deep convection and lower tropospheric stability parameter range for low clouds can be inferred from this study and worked into models' cloud parameterizations. Continued work will be conducted to examine more aspects of cloud properties, such as cloud fraction, cloud top height and cloud radiative effects, by combining multisatellite measurements such as CloudSat, CALIPSO and other instruments.

[46] Acknowledgments. We thank the support from the JPL strategic R\&TD project and the CloudSat mission team. This work was carried out at the Jet Propulsion Laboratory, California Institute of Technology, under contract with NASA. J.T. acknowledges the support provided by the Office of Naval Research Marine Meteorology Program under award N0001408IP20064 and by the NASA MAP Program. X.H., as a GFDL collaborator, is extremely grateful for the generous computing time provided by the NOAA GFDL and V. Ramaswamy. X.H. is partly supported by the NASA MAP project under grant NNX09AJ46G awarded to the University of Michigan. The National Center for Atmospheric Research is supported by the U. S. National Science Foundation.

\section{References}

Austin, R. T., A. J. Heymsfield, and G. L. Stephens (2009), Retrieval of ice cloud microphysical parameters using the CloudSat millimeter-wave radar and temperature, J. Geophys. Res., 114, D00A23, doi:10.1029/ 2008JD010049.

Bacmeister, J. T., M. J. Suarez, and F. R. Robertson (2006), Rain reevaporation, boundary layer-convection interactions, and Pacific rainfall patterns in an AGCM, J. Atmos. Sci., 63, 3383-3403, doi:10.1175/ JAS3791.1.

Bennhold, F., and S. Sherwood (2008), Erroneous relationships among humidity and cloud forcing variables in three global climate models, J. Clim., 21, 4190-4206, doi:10.1175/2008JCLI1969.1.

Bodas-Salcedo, A., M. J. Webb, M. E. Brooks, M. A. Ringer, K. D. Williams, S. F. Milton, and D. R. Wilson (2008), Evaluating cloud systems in the Met Office global forecast model using simulated CloudSat radar reflectivities, J. Geophys. Res., 113, D00A13, doi:10.1029/ 2007JD009620.

Bony, S., and J.-L. Dufresne (2005), Marine boundary layer clouds at the heart of tropical cloud feedback uncertainties in climate models, Geophys. Res. Lett., 32, L20806, doi:10.1029/2005GL023851.

Bony, S., J.-L. Dufresne, H. LeTreut, J.-J. Morcrette, and C. Senior (2004), On dynamic and thermodynamic components of cloud changes, Clim. Dyn., 22, 71-86, doi:10.1007/s00382-003-0369-6.

Cess, R. D., et al. (1989), Interpretation of cloud-climate feedback as produced by 14 atmospheric general circulation models, Science, 245, 513-516, doi:10.1126/science.245.4917.513.

Cess, R. D., et al. (1996), Cloud feedback in atmospheric general circulation models: An update, J. Geophys. Res., 101, 12,791-12,794, doi:10.1029/ 96JD00822.

Collins, W. D., P. J. Rasch, B. A. Boville, J. J. Hack, J. R. McCaa, D. L. Williamson, B. P. Briegleb, C. M. Bitz, S.-J. Lin, and M. Zhang (2006), The formulation and atmospheric simulation of the Community Atmosphere Model: CAM3, J. Clim., 19(11), 2122-2143, doi:10.1175/ JCLI3761.1.

Eriksson, P., M. Ekström, B. Rydberg, D. L. Wu, R. T. Austin, and D. P. Murtagh (2008), Comparison between early Odin-SMR, Aura MLS and CloudSat retrievals of cloud ice mass in the upper tropical troposphere, Atmos. Chem. Phys., 8(7), 1937-1948, doi:10.5194/acp-8-19372008.

Gettelman, A., H. Morrison, and S. J. Ghan (2008), A new two-moment bulk stratiform cloud microphysics scheme in the Community Atmospheric Model (CAM3), part II: Single-column and global results, J. Clim., 21(15), 3660-3679, doi:10.1175/2008JCLI2116.1.

Global Atmospheric Model Development Team (2004), The New GFDL global atmosphere and land model AM2-LM2: Evaluation with prescribed SST simulations, J. Clim., 17(24), 4641-4673, doi:10.1175/ JCLI-3223.1.

Haladay, T., and G. Stephens (2009), Characteristics of tropical thin cirrus clouds deduced from joint CloudSat and CALIPSO observations, J. Geophys. Res., 114, D00A25, doi:10.1029/2008JD010675.

Huang, X. L., V. Ramaswamy, and M. Daniel Schwarzkopf (2006), Quantification of the source of errors in AM2 simulated tropical clear-sky outgoing longwave radiation, J. Geophys. Res., 111, D14107, doi:10.1029/ 2005JD006576.

Intergovernmental Panel on Climate Change (2007), Climate Change 2007: The Physical Science Basis-Contribution of Working Group I to the Fourth Assessment Report of the Intergovernmental Panel on Climate Change, edited by S. Solomon et al., Cambridge Univ. Press, Cambridge, U. K.

Klein, S. A., and D. L. Hartmann (1993), The seasonal cycle of low stratiform clouds, J. Clim., 6, 1587-1606, doi:10.1175/1520-0442(1993)006<1587: TSCOLS $>2.0 . \mathrm{CO} ; 2$.

L'Ecuyer, T. S., and J. H. Jiang (2010), Touring the atmosphere aboard the A-Train, Phys. Today, 63(7), 36-41, doi:10.1063/1.3463626.

Li, J.-L., J. H. Jiang, D. E. Waliser, and A. M. Tompkins (2007), Assessing consistency between EOS MLS and ECMWF analyzed and forecast estimates of cloud ice, Geophys. Res. Lett., 34, L08701, doi:10.1029/ 2006GL029022

Li, J.-L., D. Waliser, C. Woods, J. Teixeira, J. Bacmeister, J. Chern, B.-W. Shen, A. Tompkins, W.-K. Tao, and M. Köhler (2008), Comparisons of satellites liquid water estimates to ECMWF and GMAO analyses, 20th century IPCC AR4 climate simulations, and GCM simulations, Geophys. Res. Lett., 35, L19710, doi:10.1029/2008GL035427.

Lin, S.-J. (2004), A vertically Lagrangian finite-volume dynamical core for global models, Mon. Weather Rev., 132, 2293-2307, doi:10.1175/15200493(2004)132<2293:AVLFDC $>2.0$. CO;2.

Moorthi, S., and M. J. Suarez (1992), Relaxed Arakawa-Schubert. A parameterization of moist convection for general circulation models, Mon. Weather Rev., 120, 978-1002, doi:10.1175/1520-0493(1992) 120<0978:RASAPO $>2.0$. CO;2.

Neale, R. B., J. H. Richter, and M. Jochum (2008), The impact of convection on ENSO: From a delayed oscillator to a series of events, J. Clim., 21, 5904-5924, doi:10.1175/2008JCLI2244.1.

Rienecker, M. M., et al. (2008), The GEOS5 Data Assimilation SystemDocumentation of Versions 5.0.1, 5.1.0, and 5.2.0, Tech. Rep. Ser. on 
Global Model. and Data Assimilation, edited by M. J. Suarez, NASA Tech. Memo., TM-2008-104606, vol. 27.

Rossow, W. B., G. Tselioudis, A. Polak, and C. Jakob (2005), Tropical climate described as a distribution of weather states indicated by distinct mesoscale cloud property mixtures, Geophys. Res. Lett., 32, L21812, doi:10.1029/2005GL024584.

Stephens, G. L. (2005), Cloud feedbacks in the climate system: A critical review, J. Clim., 18, 237-273, doi:10.1175/JCLI-3243.1.

Su, H., D. E. Waliser, J. H. Jiang, J.-L. Li, W. G. Read, J. W. Waters, and A. M. Tompkins (2006), Relationships of upper tropospheric water vapor, clouds and SST: MLS observations, ECMWF analyses and GCM simulations, Geophys. Res. Lett., 33, L22802, doi:10.1029/ 2006GL027582.

Su, H., J. H. Jiang, D. G. Vane, and G. L. Stephens (2008), Observed vertical structure of tropical oceanic clouds sorted in large-scale regimes, Geophys. Res. Lett., 35, L24704, doi:10.1029/2008GL035888.

Su, H., J. H. Jiang, G. L. Stephens, D. G. Vane, and N. J. Livesey (2009), Radiative effects of upper tropospheric clouds observed by Aura MLS and CloudSat, Geophys. Res. Lett., 36, L09815, doi:10.1029/ 2009GL037173

Sud, Y., and G. K. Walker (1999), Microphysics of Clouds with the Relaxed Arakawa Schubert Scheme (McRAS). Part I: Design and evaluation with GATE Phase III data, J. Atmos. Sci., 56, 3196-3220, doi:10.1175/1520-0469(1999)056<3196:MOCWTR >2.0.CO;2.

Waliser, D. E., et al. (2009), Cloud ice: A climate model challenge with signs and expectations of progress, J. Geophys. Res., 114, D00A21, doi:10.1029/2008JD010015.

Waliser, D. E., J.-L. F. Li, T. S. L'Ecuyer, and W.-T. Chen (2011), The impact of precipitating ice and snow on the radiation balance in global climate models, Geophys. Res. Lett., 38, L06802, doi:10.1029/ 2010GL046478.
Weng, F., and N. C. Grody (1994), Retrieval of cloud liquid water using the special sensor microwave imager (SSM/I), J. Geophys. Res., 99, 25,535-25,551, doi:10.1029/94JD02304.

Wentz, F. J. (1997), A well calibrated ocean algorithm for special sensor microwave/imager, J. Geophys. Res., 102, 8703-8718, doi:10.1029/ 96JC01751

Williams, K. D., M. A. Ringer, and C. A. Senior (2003), Evaluating the cloud response to climate change and current climate variability, Clim. Dyn., 20, 705-721.

Wu, D. L., et al. (2009), Comparisons of global cloud ice from MLS, CloudSat, and correlative data sets, J. Geophys. Res., 114, D00A24, doi:10.1029/2008JD009946.

Wyant, M. C., C. S. Bretherton, J. T. Bacmeister, J. T. Kiehl, I. M. Held, M. Zhao, S. A. Klein, and B. A. Soden (2006), A comparison of lowlatitude cloud properties and their response to climate change in three AGCMs sorted into regimes using mid-tropospheric vertical velocity, Clim. Dyn., 27, 261-279, doi:10.1007/s00382-006-0138-4.

Zhang, D., Z. Wang, and D. Liu (2010), A global view of midlevel liquidlayer topped stratiform cloud distribution and phase partition from CALIPSO and CloudSat measurements, J. Geophys. Res., 115, D00H13, doi:10.1029/2009JD012143.

Zhang, Y., et al. (2007), Cluster analysis of tropical clouds using CloudSat data, Geophys. Res. Lett., 34, L12813, doi:10.1029/2007GL029336.

A. Gettelman, National Center for Atmospheric Research, Boulder, CO 80307, USA.

X. Huang, Department of Atmospheric, Oceanic, and Space Sciences, University of Michigan, Ann Arbor, MI 48109, USA.

J. H. Jiang, V. S. Perun, G. Stephens, H. Su, J. Teixeira, and D. Vane, Jet Propulsion Laboratory, California Institute of Technology, 4800 Oak Grove Dr., M/S 183-701, Pasadena, CA 91109-8099, USA. (hui.su@jpl. nasa.gov) 